\title{
Destructive and Non-destructive Assessment of the Thickness of Oxide Layers of Super-he- ater Tubes
}

Jana Veselá, Pavel Mares, Petra Bublikova

Research Center Rez, Hlavni 130, 250 68, Husinec-Rez, Czech Republic. E-mail: jana.vesela@cvrez.cz

Tubes of super-heaters and heaters used in conventional power plants are exposed to coolant and high temperatures. The growing oxide layer on the inner surface reacts over time as a heat insulator on the water side and reduces heat transfer through the wall of the tube. A relatively thin oxide layer already contributes to the boiler efficiency and causes a permanent overheating of the tube wall. As a result of overheating at the site, the intercrystalline cracks leading to the bursting of the tube are developing. The secondary problem of the growth of oxide layer thickness is so-called exfoliation. For non-destructive evaluation of the thickness of the oxide layer directly at the power station, ultrasonic method (UT) can be used with a high frequency probe. In order to verify the accuracy of the measurement and the qualification of the ultrasonic testing methodology, light and Scanning Electron Microscopy (SEM) was used on specimens that were removed from the super-heater after the UT measurement. The standard longitudinal cut surface imaging in BackScatter Electrons (BSE) and Energy Dispersive Spectroscopy (EDS) analysis for accurate thickness determination with the chemical composition of the layer confirmed the accuracy of the UT measurement.

Keywords: Ultrasonic testing, Scanning Electron Microscopy, Heater, Oxide layer, Thickness measurement

\section{The principle of formation of the oxide layer}

Tubes in fossil-fired boilers operating at temperatures above $500{ }^{\circ} \mathrm{C}$ are exposed to the formation of an internal oxide layer on the water side. A specific type of hard, brittle oxide layer (magnetite $\mathrm{Fe} 3 \mathrm{O} 4$ ) forms on both tube surfaces. The formation of the oxide layer at high thermal loads, where water vapor reacts with iron in a steel tube to form magnetite and hydrogen, is described in the following formula: $3 \mathrm{Fe}+4 \mathrm{H} 2 \mathrm{O}=\mathrm{Fe} 3 \mathrm{O} 4+4 \mathrm{H} 2$.

The reaction rate is time-varying, so the magnetite formation process starts slowly and accelerates with the rising temperature of the tube wall. The oxygen atoms diffuse inward through the magnetite layer, while the iron atoms diffuse towards the outer surface. The growth of the oxide layer continues even after full coverage of the tube surface. The thermal conductivity of the magnetite layer is only $5 \%$ of the thermal conductivity of the steel base material. This fact plays a significant role in inefficient heat transfer and the tube wall is permanently overheated in the operating temperature range. [1]

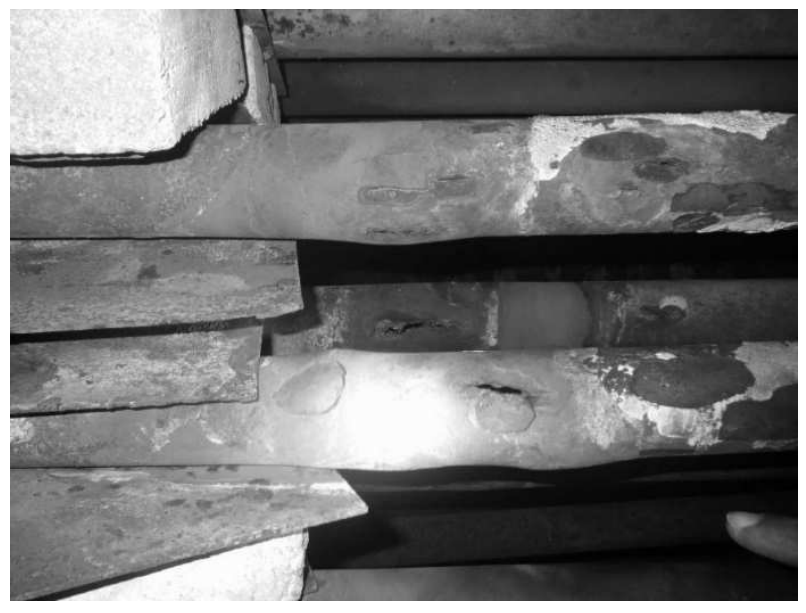

Fig. 1 Tube damage by local creep deformation and macro-crack development
Long-term thermal exposure combined with high internal water pressure in the tube leads to the development of micro cracks in steel. In addition, deformation due to the creep of steel leads to a gradual expansion and buckling of the surface, as shown in Fig. 1. From a long-term perspective, these operating conditions result in rupture of the tube, Fig. 2. Damage to the tube base material due to the growth of the oxide layer leading to the development of microcracks and the formation of creep distortions is a limiting factor for the lifetime of the boiler tubes.

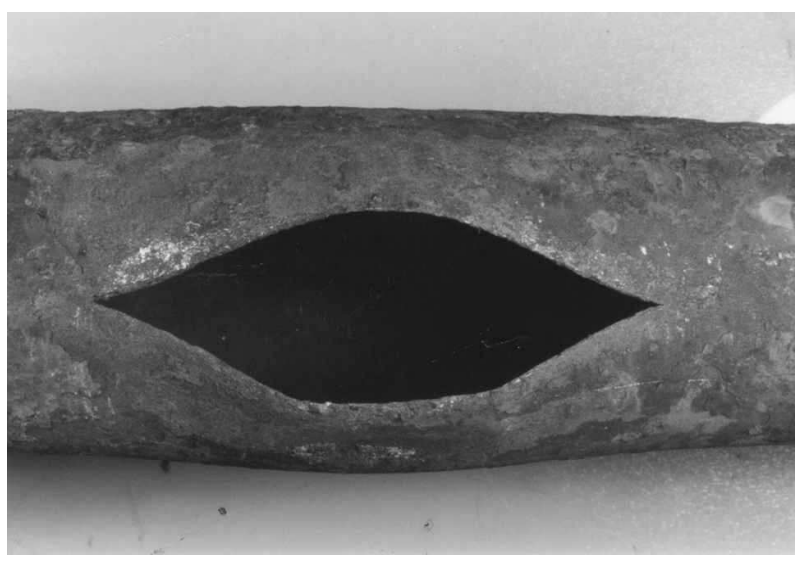

Fig. 2 Surface buckling and tube rupture

Studies from energy industry have shown that the influence of the inner oxide layer is relatively insignificant to a thickness of about $0.3 \mathrm{~mm}$. Negative effects, however, are rapidly rising above this value [3]. Periodic measurements of the internal thickness of the oxide layer allow the plant operator to estimate the remaining tube lifetime and to replace the tubes that are approaching the failure in time.

The non-destructive UT method, using the device and settings mentioned below, allows the thickness to be measured from about $200 \mu \mathrm{m}$ to the order of millimeters. The correct setting of the ultrasound device and the fact of the 
corresponding measured thickness of the oxide layer were verified destructively by metallographic analysis of the tubes removed from the super-heater. Both light and scanning electron microscopy were used for the analysis.

\section{Ultrasonic testing}

To measure the thickness of inner oxide layer a pulse echo technique of testing using the high-frequency direct probe, broadband and transverse waves is used. The thickness of the inner oxide layer is calculated based on the distance between the respective measured echoes [2]. The first echo is a reflection of the steel-oxide interface and the second echo from the oxygen-air interface on the inner surface of the tube, as shown in Fig. 3.

The use of this specialized ultrasonic technique requires the preparation of the surface of the tube at the site to ensure coupling of the probe with the surface and allows the evaluation of a large number of measurements in a relatively short time.

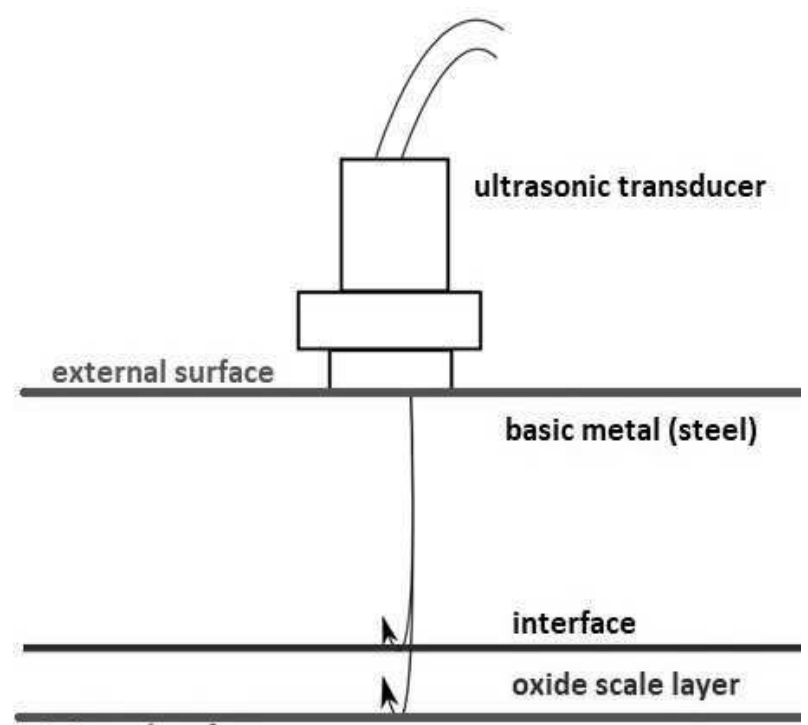

internal surface

Fig. 3 Principle of ultrasonic measurement

The Epoch 600 ultrasonic instrument uses a maximum impulse energy of $400 \mathrm{~V}$ for the ultrasonic pulse. The device software precisely measures a short time interval between two peaks of echoes from the interface between the steel - the oxide layer and the oxide layer - air. The device takes into account the time of ultrasound passing through the wall of the tube and tube material.

The $20 \mathrm{MHz}$ high-frequency transverse wave probe is used for measurement. An acoustic bond enabling the direct transfer of ultrasound transverse waves into the material is ensured by a special acoustic couplant (Sonotech - shear wave gel). Transverse waves compared to longitudinal waves have a shorter wavelength, i.e. higher resolution when measured.

Surface preparation for measuring the thickness of the inner oxide layer is necessary and the oxidation layer must be removed on the outer surface of the tube, most often by grinding, Fig. 4. Smooth, clean and flat surface allows correct contact of the probe and proper measure- ment of the thickness of the oxide layer on the inner surface or thickness of the base material of the tube. The clean areas on the surface are $20 \times 30$ or $10 \times 150 \mathrm{~mm}$ depending on the number of measured points and the diameter of the tube.

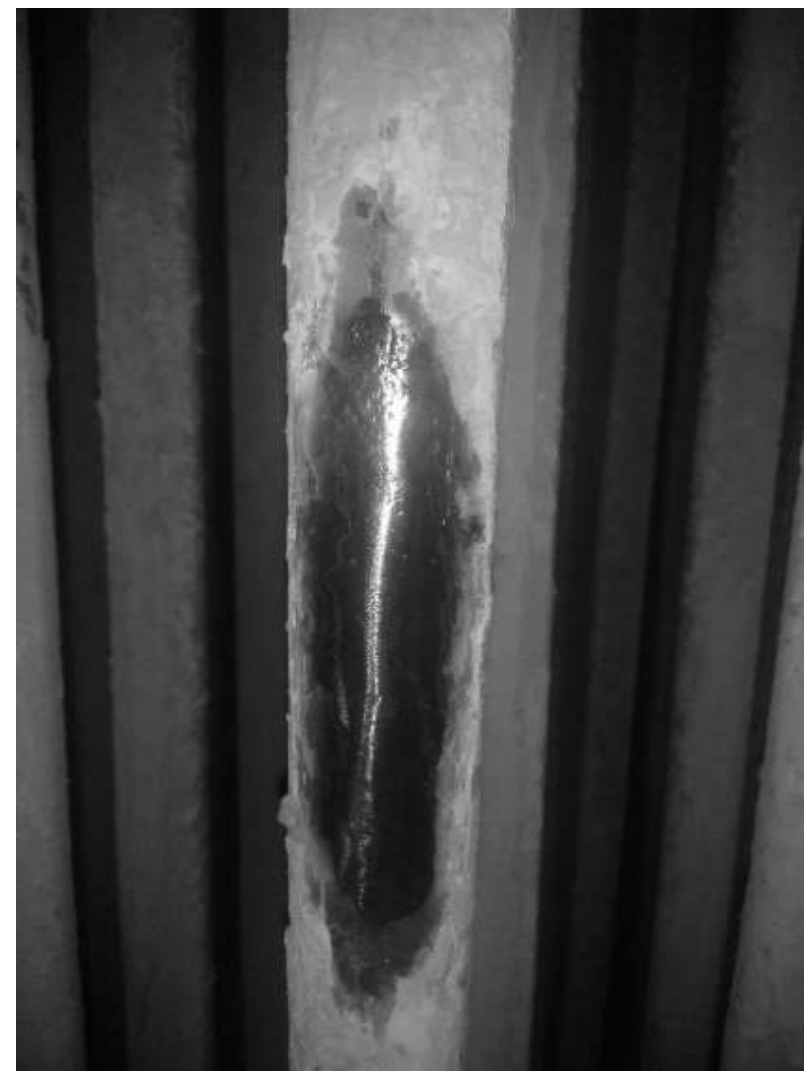

Fig. 4 Ground place for UT inspection, surface detail

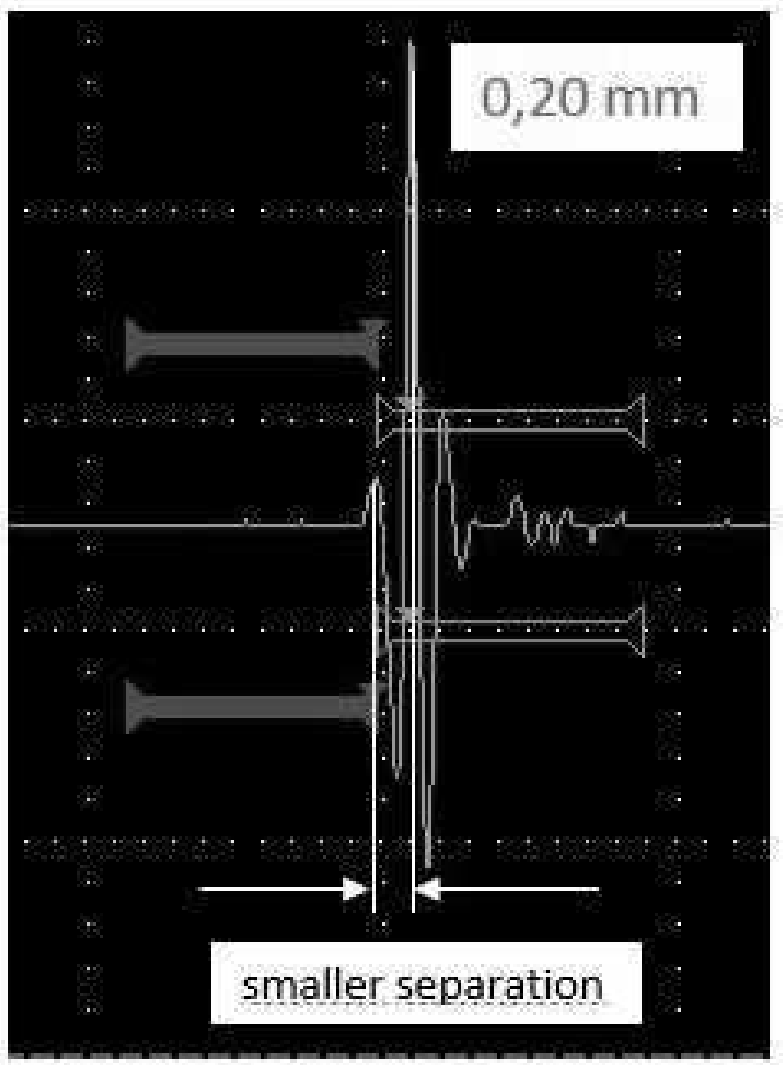

Fig. 5 Measured oxide thickness $0,2 \mathrm{~mm}$ 


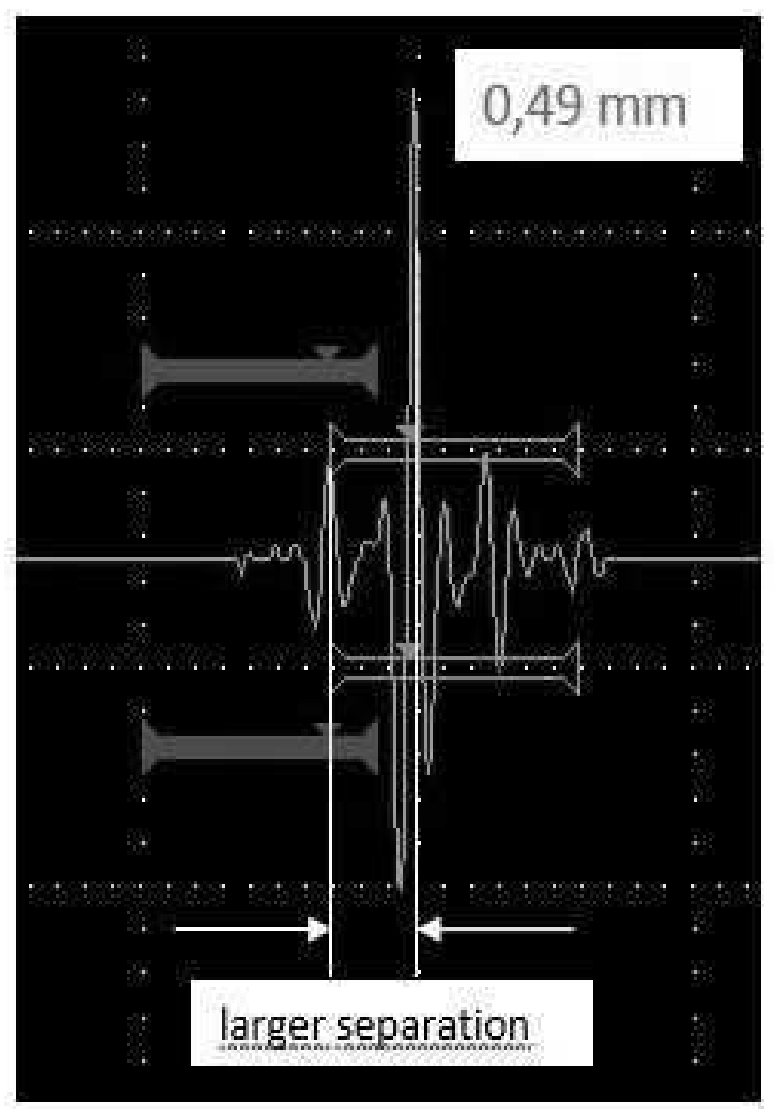

Fig. 6 Oxide thickness $0,49 \mathrm{~mm}$
Comparison of the resolution of two signals on the Ascan performed on two tubes of different thickness of the oxide layer is shown in Fig. 5 and 6. In Fig. 5, a limiting oxide thickness of $0.2 \mathrm{~mm}$ is measured. Decreasing oxide thickness decreases the mutual resolution between echoes from the interface between the steel - oxide and the air oxide. Fig. 6 shows an optimal axial resolution from the interface at a thickness of $0.49 \mathrm{~mm}$.

\section{Tube base material}

Measured tubes are made of heat-resistant materials in accordance with Czech standards named ČSN 415128 and ČSN 415313 or stainless steel according to ČSN 41 7341. Chemical compositions of appointed steels are listed in Table 1.

\section{Metallography of oxide layers}

Correct measurement of the thickness of the inner oxide layer by ultrasound was verified by metallographic analysis on samples from tubes removed from the boiler due to an unsatisfactory result of ultrasonic inspection. Samples were cut in the axial direction of the tube with a precision diamond-saw blade, ground and polished to evaluate the thickness of the oxide layer on the longitudinal section. The method of light and scanning electron microscopy was used to verify the proposed methodology and correct setting of all parameters of non-destructive testing by the ultrasonic method.

Tab. 1 Chemical composition of heat-resistant steels

\begin{tabular}{|c|c|c|c|c|c|c|c|}
\hline \multicolumn{7}{|c|}{ Normalised chemical composition (\% by weight) - low-alloy heat-resisting steel 15128} \\
\hline $\mathrm{C}$ & $\mathrm{Si}$ & $\mathrm{Mn}$ & $\mathrm{P}$ & $\mathrm{S}$ & $\mathrm{Cr}$ & $\mathrm{Mo}$ & $\mathrm{V}$ \\
\hline $0,1-0,18$ & $0,15-0,4$ & $0,45-0,70$ & $\leq 0,040$ & $\leq 0,040$ & $0,5-0,75$ & $0,40-0,60$ & $0,22-0,35$ \\
\hline
\end{tabular}

\begin{tabular}{|c|c|c|c|c|c|c|}
\hline \multicolumn{6}{|c|}{ Normalised chemical composition (\% by weight) - low-alloy heat-resistant steel 15313} \\
\hline $\mathrm{C}$ & $\mathrm{Si}$ & $\mathrm{Mn}$ & $\mathrm{P}$ & $\mathrm{S}$ & $\mathrm{Cr}$ & $\mathrm{Mo}$ \\
\hline $0,08-0,15$ & $0,15-0,4$ & $0,40-0,80$ & $\leq 0,035$ & $\leq 0,035$ & $2-2,5$ & $0,90-1,10$ \\
\hline
\end{tabular}

\begin{tabular}{|c|c|c|c|c|c|c|c|}
\hline \multicolumn{7}{|c|}{ Normalised chemical composition (\% by weight) - high-alloy heat-resistant steel 17341} \\
\hline $\mathrm{C}$ & $\mathrm{Si}$ & $\mathrm{Mn}$ & $\mathrm{P}$ & $\mathrm{S}$ & $\mathrm{Cr}$ & $\mathrm{Ni}$ & $\mathrm{Mo}$ \\
\hline $0,04-0,10$ & $\leq 2,0$ & $\leq 0,80$ & $\leq 0,045$ & $\leq 0,030$ & $16-18$ & $11,5-14$ & $2,0-2,8$ \\
\hline
\end{tabular}

The image obtained by the light microscope compared with the ultrasound thickness measurement is illustrated in Fig. 7. From light microscopy images, it is clear that for the more accurate thickness measurement, the surface preparation quality and the oxidation layer - the base material - must be highlighted. The metallographic cuttings were therefore finely ground and polished for SEM analysis.

The thickness variation of the oxide layer depends on the initial state of the inner surface of the tube due to the manufacturing process, operating parameters (e.g. temperature), time and chemical mode of the coolant. From the SEM images, it is clear that the oxide layer is Fe-O based, where the bottom layer is then diffused by chromium.
The thickness of the layer measured in BackScatter Electrons (BSE) showing the chemical contrast of the oxide / base material was confirmed by linear EDS analysis based on the concentration of the individual elements (decrease of O, increase of Fe); Fig. 8.

SEM analysis was performed on 2 sample tubes $38 \times 5$ and $38 \times 7 \mathrm{~mm}$. On a sample of the $38 \times 5$ tube, 18 measured points with an oxide layer average of the thickness 367.5 $\mu \mathrm{m}$ were measured on side 1 and a total of 20 measured points with an average value of $444.7 \mu \mathrm{m}$ measured on side 2.

Results of the $38 \times 7$ sample are summarized and listed in Table 2. 

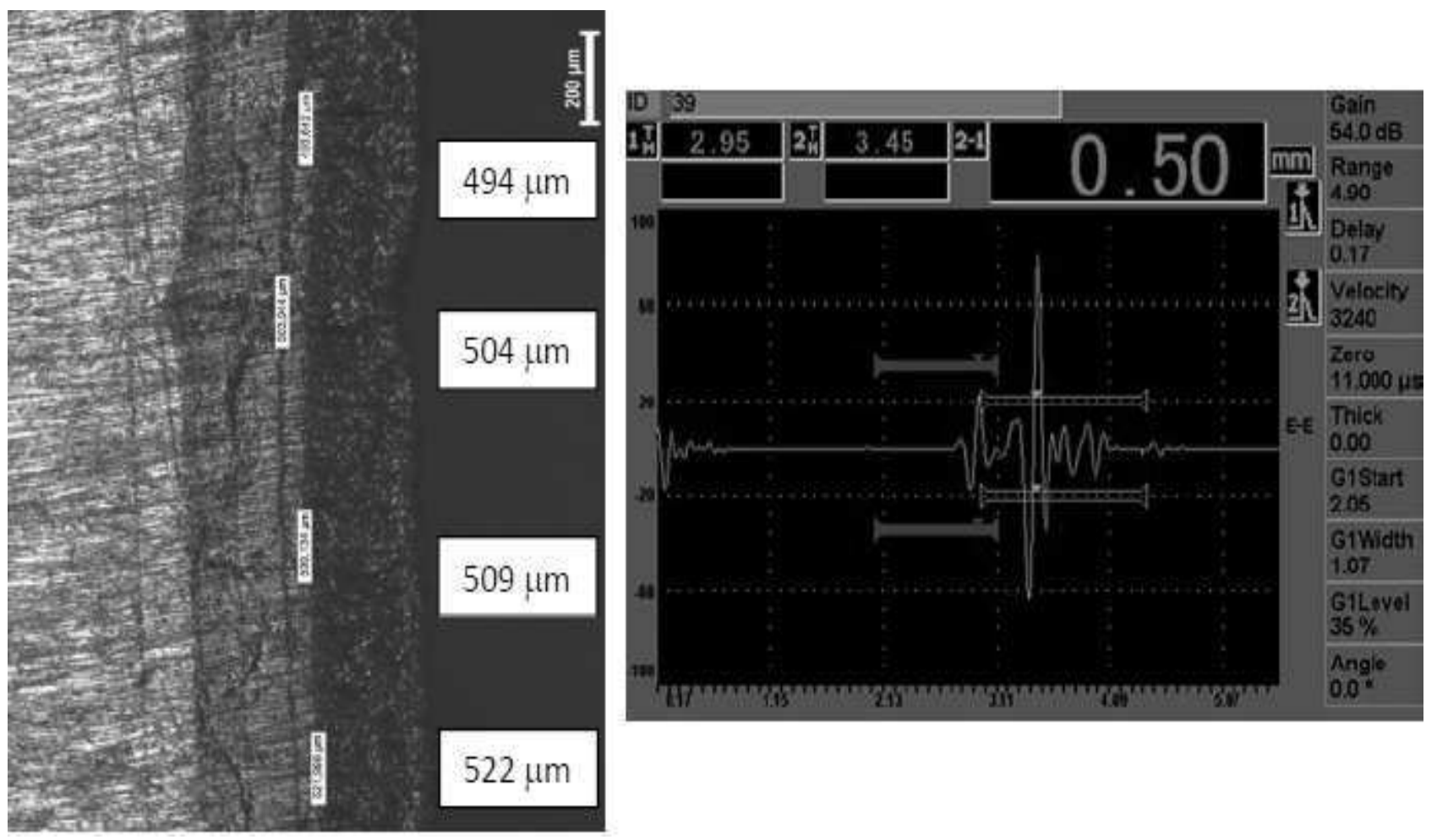

Fig. 7 Comparison of light microscopy and ultrasound measurement results

Tab. 2 Layer thickness measurement on SEM from BSE images, tube $38 \times 7 \mathrm{~mm}$

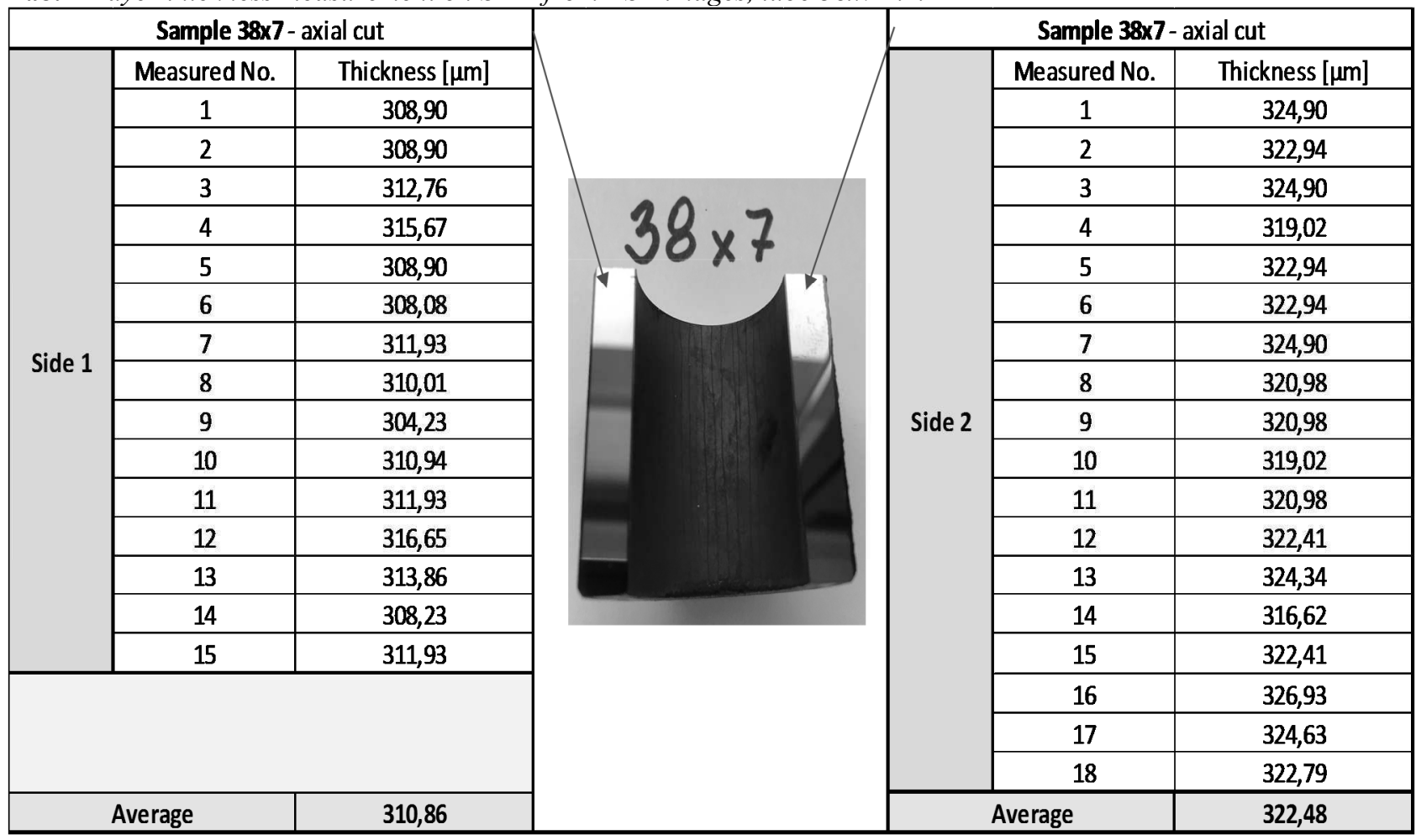

Due to the probe diameter $5 \mathrm{~mm}, 4$ positions are measured on each side of the sample by ultrasound. The measured results of the thickness of the inner oxide layer, including their average, are given in Table 3.
The result of ultrasonic measurement on a sample of $38 \times 7$ at one of 4 positions corresponding to the measurement of the thickness of the inner oxidation layer by SEM is shown in Figure 9. 


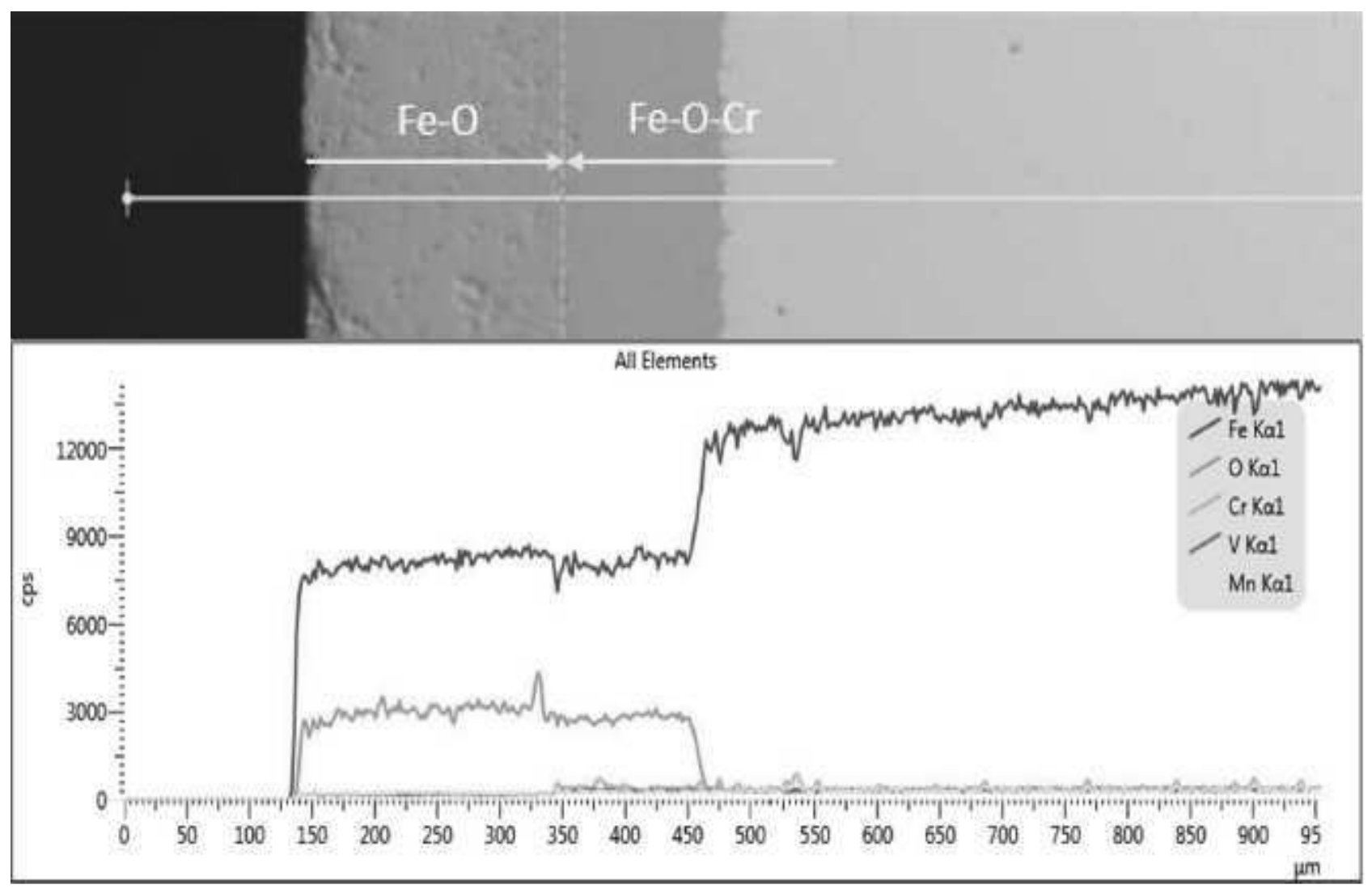

Fig. 8 Line EDS analysis of the oxide layer on sample 38x7, side 2

Tab. 2 Ultrasonic measurement results on $38 \times 5$ and $38 \times 7$ samples

\begin{tabular}{|c|c|c|c|c|c|}
\hline \multicolumn{3}{|c|}{ Sample 38x5 (axial cut) } & \multicolumn{3}{|c|}{ Sample $38 \times 5$ (axial cut) } \\
\hline \multirow{5}{*}{ Side 1} & Meas. No. & Thickness $[\mu \mathrm{m}]$ & \multirow{5}{*}{ Side 2} & Meas. No. & Thickness $[\mu \mathrm{m}]$ \\
\hline & 1 & 430 & & 1 & 430 \\
\hline & 2 & 360 & & 2 & 430 \\
\hline & 3 & 320 & & 3 & 430 \\
\hline & 4 & 380 & & 4 & 440 \\
\hline \multicolumn{2}{|c|}{ Average } & 372,5 & \multicolumn{2}{|c|}{ Average } & 432,5 \\
\hline \multicolumn{3}{|c|}{ Sample 38x7 (axial cut) } & \multicolumn{3}{|c|}{ Sample 38x7 (axial cut) } \\
\hline \multirow{5}{*}{ Side 1} & Meas. No. & Thickness $[\mu \mathrm{m}]$ & \multirow{5}{*}{ Side 2} & Meas. No. & Thickness $[\mu \mathrm{m}]$ \\
\hline & 1 & 310 & & 1 & 320 \\
\hline & 2 & 310 & & 2 & 320 \\
\hline & 3 & 310 & & 3 & 310 \\
\hline & 4 & 310 & & 4 & 320 \\
\hline \multicolumn{2}{|c|}{ Average } & 310 & \multicolumn{2}{|c|}{ Average } & 317,5 \\
\hline
\end{tabular}



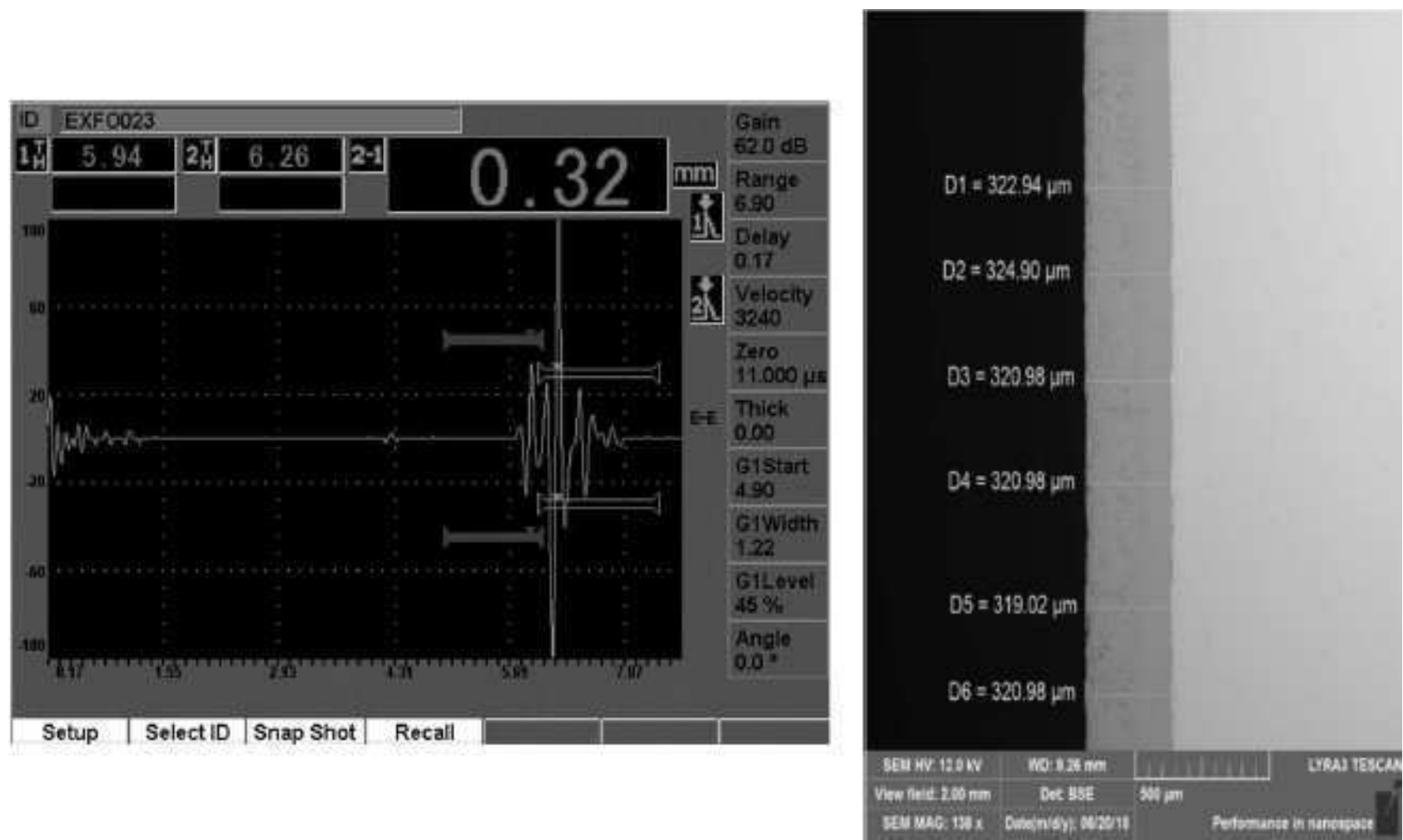

Fig. 9 Comparison of UT results and SEM analysis on sample 38x7, side 2

\section{Chemical composition of oxide layer}

In the verification measurements of the thickness of the oxide layer other than the ultrasonic method it was found that the layer exhibited magnetic properties. A more detailed analysis of the Raman microscope yielded the spectrum in figure 10 . The intensity range of 64 to 122 cps and a shift of 100 to $1800 \mathrm{~cm}-1$. Spectrum evaluation confirmed the presence of magnetite. [4]

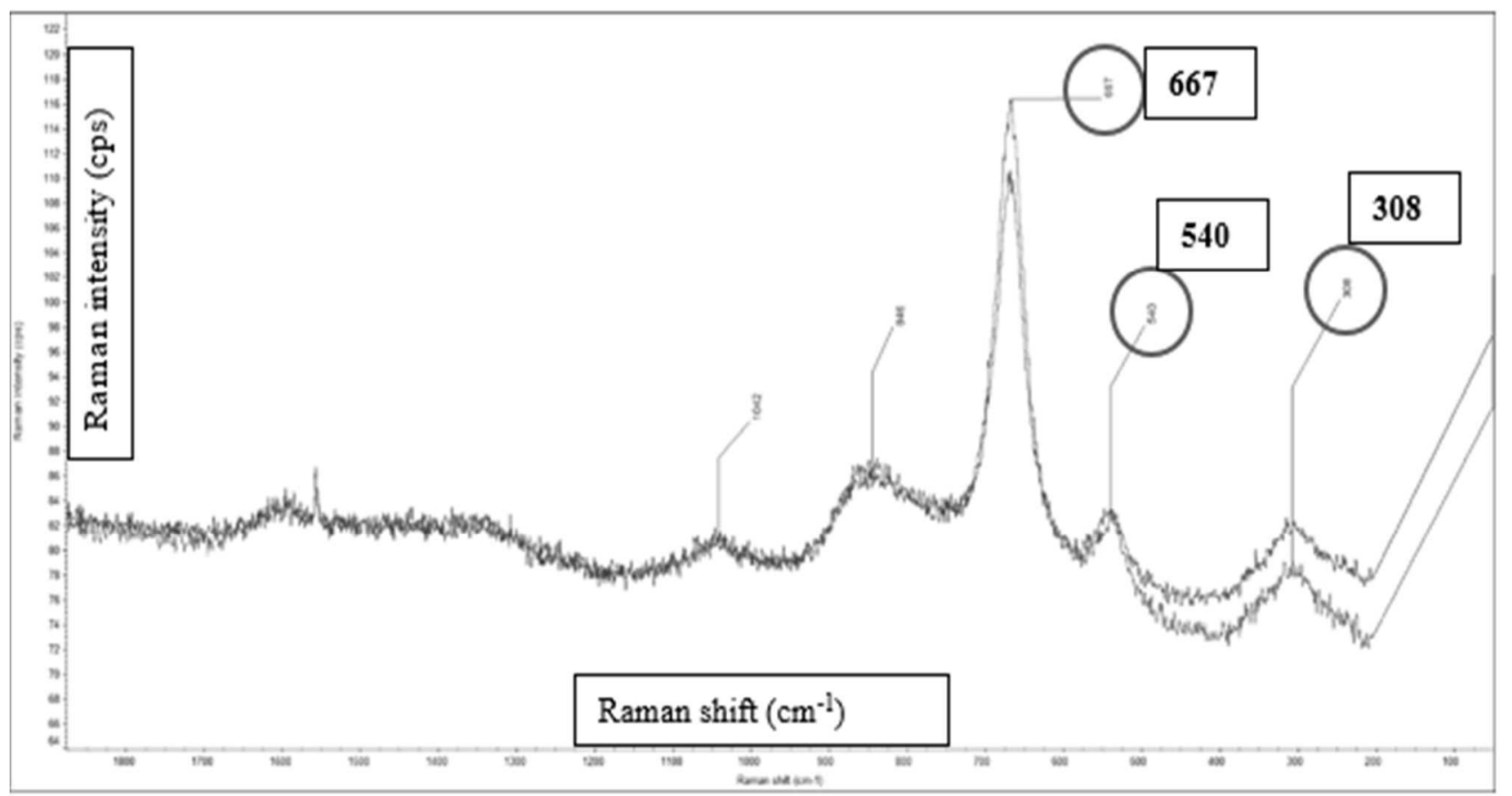

Fig. 10 Raman's spectroscopy of internal oxide layer

\section{Conclusion}

The measurement of the thickness of the oxide layers on the inner surface of the heaters and super-heater tubes by the ultrasonic method has already been implemented in more than 10 projects at several fossil power plants in the Czech Republic. In total, more than 600 selected locations were checked according to the requirements of the 
contractors.

The chosen comparative method of thickness measurement by Scanning Electron Microscopy using BSE imaging and EDS methods confirms the results of UT measurements. It can be seen that the measured values, as well as their diameters, shown in Tables 2 and 3, are in very good agreement. The measurement results of the UT method can be guaranteed with \pm 25 microns. The testing methodology has been successfully qualified for company ČEZ a.s.

\section{Acknowledgement}

The presented work was financially supported by the Ministry of Education, Youth and Sport Czech Republic Project LQ1603 (Research for SUSEN). This work has been realized within the SUSEN Project (established in the framework of the European Regional Development Fund (ERDF) in project CZ.1.05/2.1.00/03.0108).

\section{References}

[1] FRENCH, DAVID N. (1983). Metallurgical Failures in Fossil Fired Boilers, John Wiley \& Sons, New York, pp. 143-145

[2] PALO ALTO (2013). Boiler Tube Internal Oxide Scale Thickness Measurement, EPRI doc. 3002002053, California, USA
[3] YAMANI A. (2009). Measuring Oxide Scale Thickness on The Inner Surface of a Boiler Tube Using Advanced Ultrasonic Method, 5th Middle East ASNT Conference, pp. 1-2

[4] HANESCH M. (2009). Raman spectroscopy of iron oxides and (oxy)hydroxides at low laser power and possible applications in environmental magnetic studies, Geophysical Journal International, pp. 941-948

[5] NACHTNEBL P., KOLARIK L., FOREJTOVA L., REISGEN U., BEHR W. (2018). Ultrasonic testing of diffusion bonded joints of AlMg3. In Manufacturing Technology, Vol. 18, No. 2, pp. 289-294.

[6] KNAISLOVA A., SIMUNKOVA V., NOVAK P. (2018), High-temperature Oxidation of Intermetallics Based on Ti-Al-Si Systém. In Manufacturing Technology, Vol. 18, No. 2, pp. 255-258.

[7] CARNOGURSKA M., PRIHODA M., SKOCILASOVA B., CERVENKA B. (2017), Heat Loading of Steam Boilers Heating Surfaces In Manufacturing Technology, Vol. 17, No. 2, pp. 157-163. 